Rapport - Société canadienne d'histoire de l'Église catholique

\title{
Rapport du Secrétaire adjoint de la section française
}

\section{Raymond Massé}

Volume 32, 1965

URI : https://id.erudit.org/iderudit/1007325ar

DOI : https://doi.org/10.7202/1007325ar

Aller au sommaire du numéro

Éditeur(s)

Les Éditions Historia Ecclesiæ Catholicæ Canadensis Inc.

ISSN

0318-6148 (imprimé)

1927-7075 (numérique)

Découvrir la revue

Citer ce document

Massé, R. (1965). Rapport du Secrétaire adjoint de la section française. Rapport -

Société canadienne d'histoire de l'Église catholique, 32, 9-10.

https://doi.org/10.7202/1007325ar

Tous droits réservés @ Les Éditions Historia Ecclesiæ Catholicæ Canadensis Inc., 1966
Ce document est protégé par la loi sur le droit d'auteur. L’utilisation des services d'Érudit (y compris la reproduction) est assujettie à sa politique d'utilisation que vous pouvez consulter en ligne.

https://apropos.erudit.org/fr/usagers/politique-dutilisation/ 


\section{Rapport du Secrétaire adjoint de la section française}

La Société Canadienne d'Histoire de l'Eglise Catholique a tenu son congrès annuel à l'Hôtel-Dieu Saint-Vallier, à Chicoutimi, les samedi et dimanche 16 et 17 octobre 1965.

Le dimanche 17 octobre, à dix heures de l'avant-midi, au Séminaire de Chicoutimi, sous la présidence de Mgr Victor Tremblay, p.d., président de la section, a eu lieu l'assemblée du Conseil d'administration.

Les personnes suivantes étaient présentes : Mgr Victor Tremblay, p.d., Mgr Maurice O'Bready, p.d., le R.P. Gaston Carrière, o.m.i., Mme Reine Malouin, M. l'abbé Honorius Provost, M. l'abbé Michel Le Moignan, M. l'abbé François Beaudin, M. Albert Saint-Jean, M. Conrad Charlebois, M. Jean-Claude Hudon et M. Raymond Massé.

Il a été proposé par Mme Reine Malouin, appuyé par M. l'abbé Michel Le Moignan, que le rapport du secrétaire de la réunion d'octobre 1964 soit accepté.

Le trésorier a présenté son rapport financier. Il a été accepté sur proposition de M. l'abbé Michel Le Moignan, appuyée par M. Albert Saint-Jean.

Le responsable des relations extérieures a présenté un rapport des activités de son comité. Il a noté le peu de coopération reçu de la part des grands médiums d'information, tels que la radio et la télévision. Il estime cependant qu'un travail soutenu de notre part pourra apporter des résultats dans les années à venir.

La nomination de Mgr Victor Tremblay, p.d., au poste de président général de la Société a été acceptée et ratifiée. Il a également été décidé de demander à Son Eminence le cardinal Maurice Roy de bien vouloir accepter d'être le premier président honoraire de notre Société.

Retenu à Chicoutimi par la maladie, Mgr Victor Tremblay, p.d., n'a pu assister au congrès de la section anglaise, qui se tenait à Vancouver en juin dernier. Notre section était cependant représentée par M. Conrad Charlebois, secrétaire, et par le R.P. Gaston Carrière, o.m.i., qui y était conférencier.

Le prochain congrès annuel aura lieu à Sherbrooke, P.Q., en juin 1966, en même temps que ceux des Sociétés savantes. Mgr Maurice O'Bready, p.d., sera responsable de son organisation.

M. l'abbé François Beaudin a demandé à la Société d'étudier la possibilité d'inclure dans le * Rapport annuel " l'inventaire de la correspondance de Mgr Bourget. La raison qu'il a invoquée est qu'à partir 
de 1967, cet inventaire ne sera plus publié dans le rapport de l'archiviste de la province de Québec. A cause de l'ampleur de ce projet, l'assemblée a demandé à $M$. l'abbé Beaudin de préparer un mémoire complet sur cette affaire et de le soumettre de nouveau à la Société.

Les résultats des élections pour le Conseil d'administration ont été les suivants : président, Mgr Maurice O'Bready, p.d., Sherbrooke, P.Q.; vice-présidente, Mme Reine Malouin, Québec, P.Q.; secrétaire, M. Conrad Charlebois, Hull, P.Q.; secrétaire adjoint, M. Raymond Massé, Hull, P.O.; trésorier, le R.P. Gaston Carrière, o.m.i., Ottawa, Ont.; directeur des relations extérieures, M. Albert Saint-Jean, Verdun, P.Q.; directeurs: le R.P. Adrien Pouliot, s.j., Québec, P.Q.; la Rév. Sœur MadeleineDurand, f.c.s.p., Montréal, P.Q.; le R.P. Lorenzo Cadieux, s.j., Sudbury, Ont.; M. l'abbé Michel Le Moignan, Gaspé, P.Q.; la Rév. Sœur E. De Moissac, s.g.m., Saint-Boniface, Man.; M. Gaston Beaulieu, Toronto, Ont.; M. Jean-Claude Hudon, Chicoutimi, P.Q.

Il y a donc un poste qui est demeuré vacant chez les directeurs. Le président et le secrétaire ont été autorisés à faire une nomination à cet effet dans le plus bref délai possible.

L'assemblée a été alors levée. 